\title{
SERVIÇO SOCIAL E INTERDISCIPLINARIDADE NA ATENÇÃO BÁSICA À SAÚDE
}

\author{
Social Work and Interdisciplinarity in Health Basic Attention
}

\author{
Marta Maria da Silva ${ }^{1}$ \\ Telma Cristiane Sasso de Lima ${ }^{2}$
}

\section{RESUMO}

Trata-se do relato de experiência sobre o Serviço Social e a intervenção em equipe multiprofissional na Atenção Básica à Saúde. Apresentam-se o estudo empreendido e as aproximações crítico reflexivas realizadas a partir da participação no grupo tutorial PET Saúde da Família 2010-2011 que levaram à apreensão teórico-prática da interdisciplinaridade e da sua importância para a formação do assistente social. Assume-se como pressuposto que o exercício interdisciplinar está inscrito na Política de Saúde brasileira desde 1988, exigindo um perfil profissional de caráter generalista, envolvido com a prevenção e promoção da saúde, no contexto do SUS. Os resultados obtidos permitem pensar a interdisciplinaridade como categoria determinada pela dinâmica da realidade social, exigindo das equipes profissionais monitoramento constante de suas ações e atitude propositiva e inovadora na organização dos serviços públicos de saúde. A interdisciplinaridade tende a impulsionar a apreensão da realidade como totalidade, no conhecimento do processo saúde-doença e das demandas/necessidades dos usuários, considerados como copartícipes do processo que constrói as ações profissionais e institucionais direcionadas à concretização de uma atenção integral, buscando o acesso efetivo ao direito à saúde.

PALAVRAS-CHAVE: Serviço Social. Atenção Básica. Interdisciplinaridade. Direito à Saúde.

\begin{abstract}
It is the experience report on Social Work and intervention in the multidisciplinary team in health basic attention. We present the study undertaken and the critical-reflexive approaches taken from the participation in the tutorial group PET Family Health 2010-2011 that led to the seizure of interdisciplinary theory and practice and its importance for the formation of a social worker. Assume the assumption that interdisciplinary exercise is inscribed on the brazilian health policy since 1988, requiring a professional profile generalist character, involved with prevention and health promotion in the context of SUS. The results obtained allow to consider the interdisciplinary category as determined by the dynamics of social reality, requiring constant monitoring of the professional teams of their actions and attitude proactive and innovative in the organization of public health services. The interdisciplinarity tends to boost the understanding of reality as a whole, knowledge of the health-disease process and the demands/needs of users, coparticipants considered as the process that builds directed the
\end{abstract}

\footnotetext{
${ }^{1}$ Bacharel em Serviço Social (FSSO/UFAL, Maceió), ex-monitora/bolsista PET Saúde da Família no período 2010-2011. Assistente Social da Secretaria Municipal de Saúde de Maceió. Telefone: 82 8818-7473, e-mail: marta_mmsilva@hotmail.com.

2 Professora Assistente da Faculdade de Serviço Social (FSSO/UFAL - Maceió); tutora PET Saúde da Família 2010-2012, programa financiado com recursos do Ministério da Saúde; tutora da Residência Multiprofissional em Saúde do Adulto e Idoso no HUPAA/UFAL pelo MEC/SESU. E-mail: telmasasso@gmail.com.
} 
implementation of a comprehensive care professional and institutional actions, seeking access effective the right to health.

KEYWORDS: Social Work. Basic Attention. Interdisciplinarity. Right to Health.

\section{INTRODUÇÃO}

O debate acerca da interdisciplinaridade ocorre academicamente e nos cenários de exercício profissional, exigindo a necessidade de exercitar a visão de totalidade sobre a realidade. Este artigo sintetiza os estudos contidos no Trabalho de Conclusão de Curso “O Serviço Social e a Interdisciplinaridade na Atenção Básica à Saúde”3 e reforça a preocupação sobre a apropriação teórico-prática do conceito interdisciplinaridade, assunto que precisa ser aprofundado na busca por posturas profissionais críticas, consistentes e coerentes.

A partir da atual Política de Saúde apreende-se a prioridade legal atribuída ao exercício interdisciplinar para garantir a abordagem integral do processo saúde-doença. Portanto, trata-se de situação que incita como imperativo a realização de mudanças estruturais no âmbito acadêmico e nos serviços de saúde, uma vez que, para a consolidação do Sistema Único de Saúde (SUS) - conforme pleiteado pelo Movimento de Reforma Sanitária - requer a intervenção através de ações coletivas que respondam às exigências expressas pela dinâmica da realidade social.

Além disso, observa-se que no contexto dos serviços de saúde persiste a distância entre o discurso e a prática interdisciplinar na atuação dos profissionais, caracterizada pela insuficiência de fundamentação teórico-conceitual e prática sobre interdisciplinaridade. Tal situação, aliada às fragilidades socioinstitucionais, tende a reforçar lógicas e ações hierarquizadas entre as categorias profissionais que seguem centradas meramente nas especificidades teórico-práticas, fragmentando o trabalho e produzindo objetivos incomuns.

Trata-se de um estudo relevante para a relação teoria e prática que incide na atuação de profissionais de saúde e, portanto, para a Atenção Básica, nível de complexidade em saúde que abarca prioritariamente a família como locus privilegiado

\footnotetext{
${ }^{3}$ Apresentado à Faculdade de Serviço Social em 2011, na Universidade Federal de Alagoas como requisito parcial à obtenção do título de Bacharel em Serviço Social, sob orientação da Professora Telma Cristiane Sasso de Lima.

Serv. Soc. \& Saúde, Campinas, SP v. 11, n. 1 (13), p. 113-132 jan./ jun. 2012 ISSN 1676-6806
} 
de intervenção, cujo requisito indispensável reside na necessária interação entre os diversos saberes profissionais sobre as dimensões biopsicossociais que envolvem os sujeitos usuários. Para o Serviço Social, por ser uma profissão cuja formação é vinculada às diversas áreas de conhecimento, a postura interdisciplinar é exigida à medida que a reflexão sobre a interação entre os diferentes saberes favorece a abrangência de sua prática profissional e em equipe.

A partir de vivências no contexto da Política de Atenção Básica no município de Maceió, delimitou-se como objeto de estudo a participação dos profissionais de Serviço Social em equipes multiprofissionais com o objetivo de identificar as contribuições do assistente social no cotidiano da prática interdisciplinar, apreendendo as nuances de sua atuação no processo de trabalho em equipe.

O percurso metodológico seguido envolveu o relato de experiência no PET Saúde da Família no período de abril de 2010 a março de 2011. A coleta de dados abarcou as etapas: a) revisão teórico-conceitual sobre Atenção Básica, interdisciplinaridade, Serviço Social e demais conceitos correlatos; b) observação das ações profissionais ao longo do ano de participação no PET Saúde da Família que ocorreu na Unidade Básica de Saúde São José/Canaã, em Maceió/AL; c) sistematização das informações de campo, com análise da documentação institucional, bem como produzida pelo grupo tutorial: diário de campo, relatórios, relatos das atividades de grupos mistos e específicas, estudos socioinstitucionais e do ambiente sociocomunitário dos usuários, etc. A pesquisa orientou-se para a análise de casos concretos em sua particularidade temporal, partindo das expressões e atividades das pessoas em seus contextos locais (FLICK, 2004).

Vale ressaltar que se trata de uma investigação baseada numa abordagem que busca delinear e observar criticamente as situações registradas, de modo a correlacionálas à proposta da prática interdisciplinar, considerando o contexto social no qual procede a realidade dinâmica dos usuários. Assim, as seções que compõem este artigo evidenciam as discussões sobre a interdisciplinaridade como uma forma de organizar as ações profissionais, com vistas à contribuição para a efetivação da integralidade no acesso ao direito à saúde. 


\section{A ATENÇÃo BÁSICA No SUS E A ESTRATÉGIA SAÚDE DA FAMÍLIA}

A Política Nacional de Atenção Básica (PNAB) integra o Sistema Único de Saúde (SUS) após longo processo histórico de transformações na saúde pública brasileira. Corbo e Morosini (2005) atentam que, historicamente, a Política de Saúde é marcada por características de centralização na esfera federal e pela medicina curativa, dentre outras questões que dificultaram ações e serviços públicos para o atendimento às demandas da população.

Os marcos legais da Política de Saúde são encontrados nas deliberações da VIII Conferência Nacional de Saúde de 1986; no texto da Constituição Federal de 1988 (Artigo 196); nas regulamentações ocorridas a partir das Leis 8.080/90 e 8.142/90 (Lei Orgânica da Saúde, LOS), das Norma Operacional Básica do Sistema Único de Saúde (NOB/SUS) e Norma Operacional de Assistência à Saúde (NOAS/SUS), nas quais é reiterado e reconhecido o SUS como direito universal que deve dar acesso a toda população sem distinção e, ainda, são preconizados os determinantes socioculturais do processo saúde-doença, o dever do Estado na provisão de bens e serviços que garantam o conceito ampliado de saúde (BRASIL, 2008). Portanto, põe-se como requisito um novo perfil profissional e novos modelos de atenção centrados na prevenção e na promoção da saúde.

Entretanto, a partir dos anos 1990, tomou corpo a concepção de Estado Mínimo que encaminhou a redução do papel do Estado na execução de bens e serviços, fortalecendo o setor privado (BRAVO, 2000). Em meio às contradições ocorre a estruturação do nível de Atenção Básica no SUS, conforme a Política Nacional de Atenção Básica/2006, bem como suas Diretrizes para a Gestão, envolvendo princípios que visam um conjunto de ações de saúde no âmbito individual e coletivo, abrangendo a promoção e a proteção da saúde, a prevenção de agravos, o diagnóstico, o tratamento, a reabilitação e a manutenção da saúde (BRASIL, 2006).

Nesse sentido, a Estratégia Saúde da Família é considerada como alternativa para a reorganização dos serviços de Atenção Básica do SUS, assumindo a atenção centrada na família, no território físico e social que a envolve e em ações preventivas. A composição da equipe mínima de Saúde da Família regulamentou a interação entre as seguintes profissões: um médico generalista/de família, um enfermeiro, um auxiliar de enfermagem e 4 a 6 agentes comunitários de saúde. Quando ampliada, agrega ainda: um 
dentista, um auxiliar de consultório dentário e um técnico em higiene bucal. Sua responsabilidade consiste em acompanhar a população adstrita em uma área de abrangência que comporte de 600 a 1000 famílias, com limite máximo de 4.500 habitantes (BRASIL, 2006).

A partir do reconhecimento da autonomia municipal e de suas necessidades locorregionais, o Ministério da Saúde permite a flexibilização dos critérios de composição da equipe multiprofissional de acordo com as características sociopolíticas, econômicas e geográficas das diferentes regiões brasileiras (BRASIL, 1998). Cabe salientar que outros profissionais podem ser incorporados às Unidades Básicas, tais como: psicólogos, assistentes sociais, farmacêuticos, de acordo com as demandas e características da organização dos serviços de saúde locais cuja responsabilidade e iniciativa cabe ao entendimento do gestor municipal (BRASIL, 1997 apud RIBEIRO, 2005).

\section{INTERDISCIPLINARIDADE E EQUIPE MULTIPROFISSIONAL NA UBS SÃO JOSÉ/CANAÃ}

A interdisciplinaridade ganha relevância no mundo ocidental a partir da década de 1960, cuja apreensão histórica do conceito demarca três momentos: a década de 1970, quando se produzem estudos focados na definição conceitual de interdisciplinaridade; a década de 1980, momento em que se evidenciam debates acerca do método viabilizador do conceito de interdisciplinaridade; e a partir da década de 1990, com destaque às iniciativas de construção das bases teórico-práticas para a interdisciplinaridade (FAZENDA, 2001 apud COSTA, 2007).

A interdisciplinaridade é entendida como um método que se elabora para atender demandas, tais como: o desenvolvimento da ciência, respondendo às necessidades de criar um fundamento ao surgimento de novas disciplinas; reivindicações estudantis contra o saber fragmentado diante de uma realidade que é global e multidimensional. Nesse movimento, termina repercutindo na formação profissional e, consequentemente, incidindo na prática. Essa interconexão de saberes se realiza com a intenção de desvendar melhores métodos para planejar, tomar decisões e guiar a ação, no sentido de adquirir e fornecer informações novas, bem como diversificando as maneiras de se alcançar um objetivo, ampliando as perspectivas de resolver problemas sociais Serv. Soc. \& Saúde, Campinas, SP v. 11, n. 1 (13), p. 113-132 jan./ jun. 2012 ISSN 1676-6806 
concretos (JAPIASSU, 1976).

Para discutir o sentido preciso do termo interdisciplinaridade, é necessário entender seus elementos constitutivos que, ao se justaporem ao substantivo disciplina, permitem a seguinte interpretação: o prefixo inter é latino e significa posição ou ação intermediária, reciprocidade, ou interação que ocorre entre duas ou mais coisas ou pessoas na relação sujeito-objeto; já o sufixo dade também guarda a propriedade de substantivar alguns adjetivos, atribuindo-lhes o sentido de ação, qualidade, estado, ou ainda, modo de ser (ASSUMPÇÃO, 1991). Assim, o termo interdisciplinaridade tem por significação a ação concreta de juntar, articular diferentes conhecimentos e experiências práticas.

O que se almeja é ultrapassar teórica e praticamente as iniciativas multidisciplinares, entendidas como meras justaposições dos recursos de várias disciplinas, sem a exigência de um trabalho em equipe e coordenado, onde a solução de um só problema exige informações emprestadas de duas ou mais especialidades ou setores de conhecimento, mas não há o enriquecimento mútuo entre elas porque não há acordo prévio sobre os métodos a seguir ou sobre os conceitos a serem utilizados (JAPIASSU, 1976).

Nesse sentido, propõe-se a busca por iniciativas que caminhem na direção da interdisciplinaridade caracterizada pela "intensidade das trocas entre os especialistas e pelo grau de integração real das disciplinas". Isso vai além da "simples adição de especialidades num espaço e da mera síntese filosófica dos saberes especializados”, pois o desafio é negar e superar as fronteiras disciplinares sem perder as diferentes identidades profissionais (JAPIASSU, 1976, p. 74 -75).

A partir desse entendimento, é preciso atentar para o fato de que atuar em equipe na Atenção Básica exige profissionais críticos e reflexivos, com formação que atenda à diversidade da realidade que envolve os usuários, para desenvolver visão integral do processo saúde-doença. É importante reconhecer que as limitações postas, desde o período de formação dos profissionais, promovem o isolamento por disciplinas/áreas de conhecimento, hierarquizando saberes, reforçando status profissionais diferenciados e dificuldades em gerar um perfil profissional que considere a integralidade na atenção à saúde.

O exercício interdisciplinar pode permitir a construção de espaços novos, permeados pela reciprocidade, tanto no diálogo quanto nas vivências, para que ações e Serv. Soc. \& Saúde, Campinas, SP v. 11, n. 1 (13), p. 113-132 jan./ jun. 2012 ISSN 1676-6806 
resultados questionem os conhecimentos adquiridos e os métodos praticados, numa lógica de retroalimentação, de cooperação e de complementaridade de saberes, com perspectiva centrada na demanda/necessidade concreta do usuário.

A formação profissional está implicada no processo de efetivação do SUS, na construção de ações concretas que movimentem a estrutura político-administrativa para realizar a saúde como um direito de todos através de uma atenção universal, integral e igualitária, com a participação social. Para tanto, a produção de conhecimento e de ações interdisciplinares devem ser iniciadas e estimuladas desde a formação, requerendo mudanças nas instituições de ensino que promovam um novo perfil profissional atento às diretrizes do SUS e preocupados com a saúde pública (SANTOS; THIESEN, 2010).

O Ministério da Saúde, sobretudo a partir dos anos 2000, tem induzido a mudança na formação de Recursos Humanos na perspectiva do trabalho interdisciplinar para o SUS. Dentre as políticas indutoras estão o Programa de Reorientação da Formação Profissional em Saúde - PRO-SAÚDE - e o Programa de Educação pelo Trabalho para a Saúde - PET-SAÚDE (BRASIL, 2006), incitando a articulação (PROPET Saúde), no sentido de consolidar a reorientação da formação profissional mediante um processo que promova o reforço às ações integradas entre diferentes categorias profissionais. Através desses programas, institucionaliza-se a parceria interministerial entre Ministério da Saúde e Ministério da Educação e Cultura cujos objetivos residem em: fomentar a formação profissional articulada à Estratégia Saúde da Família; facilitar o processo de integração entre o ensino, os serviços e a comunidade; estimular a inserção das necessidades dos serviços na produção de conhecimento nos cursos de graduação (SANTOS; THIESEN, 2010).

Nessa direção, as ações profissionais descritas a seguir referem-se a algumas das atividades desenvolvidas através do grupo multiprofissional ${ }^{4}$ na UBS São José/Canaã, iniciado a partir do PET Saúde em 2010. A experiência gerou a articulação entre atividades de ensino, pesquisa e extensão que materializaram estudos e reflexões sistemáticas entre as diferentes categorias profissionais, através de oficinas, cursos e seminários sobre: Política de Saúde/SUS, Família e Proteção Social, Controle Social,

\footnotetext{
${ }^{4}$ As ações focaram na articulação ensino-serviço-comunidade, através da perspectiva do aprender fazendo, que reuniu os cursos de graduação da área da saúde da UFAL/Maceió. A metodologia consistiu em inserir os estudantes em grupos multiprofissionais induzindo o exercício de novas abordagens de ensino-aprendizagem entre profissionais de Enfermagem, Psicologia, Serviço Social; Medicina; Farmácia; Odontologia e Nutrição. Serv. Soc. \& Saúde, Campinas, SP v. 11, n. 1 (13), p. 113-132 jan./ jun. 2012 ISSN 1676-6806
} 
Planejamento Participativo, Determinantes Sociais do processo saúde/doença, etc. Tais estudos deram sustentação à construção de planos de intervenção nas UBS credenciadas ao PRO/PET- Saúde (SILVA, 2011).

O planejamento participativo realizado pelos grupos tutoriais agregou as equipes de Saúde da Família cujas ações pactuadas orientaram-se por três eixos básicos: Controle Social, Humanização na Atenção à Saúde e o Combate à Mortalidade Infantil. Todas as ações específicas e em equipe multiprofissional tiveram como referência esses eixos norteadores para que os estudantes estabelecessem seus planos de ação imersos no cotidiano socioinstitucional das UBS, sob supervisão multiprofissional de preceptores de campo e tutores acadêmicos, cumprindo carga horária mínima de 8 horas semanais, sendo prioritárias as atividades consistentes no exercício da interdisciplinaridade (SILVA, 2011).

Metodologicamente, a experiência abarcou dois momentos: ações específicas e ações em grupo misto/multidisciplinar, pautada pelo planejamento coletivo no qual as ações específicas foram organizadas e desenvolvidas de acordo com as especificidades disciplinares de cada curso envolvido; e os grupos mistos constituídos para promover espaço de interação entre dois ou mais cursos, almejando a interdisciplinaridade como prática coletiva articuladora da proposta político-pedagógica de cada curso e da vivência prática na Atenção Básica.

Na UBS São José/Canaã ${ }^{5}$ as atividades executadas articularam esforços entre as áreas de Medicina e Serviço Social, incluindo os demais profissionais da ESF na UBS (enfermeiros, técnicos de saúde e ACS). O grupo tutorial de Serviço Social partiu do planejamento participativo no PET Saúde com o mapeamento das demandas da comunidade, centrando seu plano de ação em duas das diretrizes: Controle Social e Combate à Mortalidade Infantil. A execução do plano de ação articulou os demais profissionais, reconhecendo o PET Saúde como programa de extensão da UFAL nas UBS do município (SANTOS et al., 2011).

Na dinâmica de trabalho foram propostas e executadas ações teórico-práticas viabilizadas por: oficinas socioeducativas, envolvendo palestras em sala de espera, nos

\footnotetext{
${ }^{5}$ Na referida UBS, a ESF é implantada em 1996. Atualmente, conta com três equipes denominadas de Canaã I e Canaã II, sendo a terceira destinada a atender à comunidade Santo Amaro, devido à falta de UBS nesta localidade (SANTOS et al., 2011). A UBS comporta ainda uma equipe de trabalho ampliada, composta por: assistentes sociais, psicóloga e farmacêutica. Serv. Soc. \& Saúde, Campinas, SP v. 11, n. 1 (13), p. 113-132 jan./ jun. 2012 ISSN 1676-6806
} 
grupos e na comunidade; visitas domiciliares; atendimentos individual e grupal com hipertensos, diabéticos, gestantes, idosos, adolescentes, dentre outras atividades.

O planejamento da intervenção diária envolveu etapas de estudo e discussão teórico-conceituais, favoráveis ao desempenho das atividades, atentando para: a intervenção do assistente social na Estratégia Saúde da Família, a Política de Saúde/ESF, Lei Orgânica da Assistência Social de 1993 (LOAS); Sistema Único da Assistência Social (SUAS); Determinantes Sociais da Saúde; Caderneta de Saúde do Adolescente, Controle Social, Aleitamento Materno (importância, legislação, etc.); HIV/AIDS, dentre outros recursos teóricos. As ações profissionais para atendimento de demandas singulares ocorreram através de Projeto de Intervenção ${ }^{6}$, atendendo à diretriz Mortalidade Infantil priorizada, conforme Oliveira et al. (2010), a partir da constatação de que há pouca adesão das parturientes ao aleitamento.

É importante destacar que as ações socioeducativas realizadas através de oficinas e salas de espera e desenvolvidas pelo grupo misto, estiveram orientadas numa perspectiva multiprofissional, visando socializar informações à comunidade com base em aspectos socioculturais, biológicos e político-econômicos na apreensão do processo saúde-doença e envolvendo: assistente social, médica, estagiários de Medicina, monitoras PET Saúde de Serviço Social, educador social e agentes comunitários de saúde.

Conforme Nora et al. (2009), por meio da sala de espera, é possível estimular a humanização do atendimento, de modo a proporcionar um ambiente de acolhimento aos usuários e familiares que utilizam os serviços de saúde, pois criam-se espaços de diálogo e vínculo entre usuário e profissional, constituindo-se como um suporte ao atendimento e ao cuidado integral.

Os assuntos envolvendo gravidez na adolescência foram pautas recorrentes nas oficinas socioeducativas e salas de espera desenvolvidas pelo grupo multidisciplinar, pois a adolescência é considerada como etapa da vida na qual ocorre a maturação sexual, o acirramento dos conflitos familiares e a formação e cristalização de atitudes, valores e comportamentos determinantes ao desenvolvimento humano, trazendo novas

\footnotetext{
${ }^{6}$ Foi executado através de oficinas educativas; visitas domiciliares para orientação do aleitamento materno às puérperas e demais mulheres com crianças em fase de aleitamento; salas de espera para esclarecimentos sobre a amamentação, legislação/direitos maternais e paternais, gravidez na adolescência.

Serv. Soc. \& Saúde, Campinas, SP v. 11, n. 1 (13), p. 113-132 jan./ jun. 2012 ISSN 1676-6806
} 
responsabilidades ao trabalho dos profissionais de saúde (KOLLER, 2002).

O tema HIV/AIDS foi destacado durante as salas de espera e nas informações sobre saúde, na perspectiva de construir atitudes preventivas, versando desde o esclarecimento conceitual, sintomas, formas de transmissão sobre HIV/AIDS, Saúde do Homem e da Mulher até a divulgação do serviço de Teste Rápido/Centro de Testagem e Aconselhamento (CTA) existente na UBS.

O atendimento individual, as visitas domiciliares, a articulação intersetorial e o assessoramento ao Conselho Gestor Local foram algumas das ações específicas da equipe de Serviço Social. A assessoria ao Conselho Gestor local é realizada de maneira permanente pela assistente social da UBS. Durante a experiência PET Saúde, foram potencializadas oficinas socioeducativas e palestras sobre: Participação e o Controle Social na Saúde, estimulando debates contínuos com os conselheiros gestores e possibilitando o entendimento do conselho como lócus privilegiado de discussão e deliberação das reivindicações sociocomunitárias.

As visitas domiciliares e o atendimento individual foram executados com o objetivo de orientar sistematicamente sobre o acesso a direitos/serviços públicos mediante contato com o ambiente de convívio do indivíduo e da família, captando melhor suas necessidades para referenciá-los às instituições prestadoras de serviços e cuidados especializados no atendimento das demandas mapeadas.

\section{APROXIMAÇÕES DA EXPERIÊNCIA INTERDISCIPLINAR DO SERVIÇO SOCIAL NA ATENÇÃo BÁSICA}

O Serviço Social tem um longo percurso sócio-histórico de intervenção e de relação multiprofissional na área da saúde. Desde a Constituição Federal de 1988, a categoria e entidades de representações tiveram presença significativa nos vários movimentos da área, bem como nos organismos representativos de interesses dos segmentos sociais organizados (SANTOS; SANTOS, 2010). O envolvimento ativo dos assistentes sociais nos debates que culminaram na implantação do SUS, além das particularidades da sua ação, ajudou no seu reconhecimento como profissional da saúde a partir da Resolução nº 218/1997 (BRASIL, 1997).

A intervenção do Serviço Social no do PET Saúde da Família contribuiu significativamente para o enfrentamento das expressões da questão social, devido ao 
consistente embasamento teórico das monitoras de Serviço Social que, aliado à experiência profissional da assistente social/preceptora, bem como das interações com os demais profissionais e comunidade, fortaleceu a relação teórico-prática no processo ensino-serviço.

Ao observar as ações desenvolvidas pela equipe multiprofissional na UBS, percebe-se que foram produtivas no sentido da aproximação às iniciativas interdisciplinares, envolvendo diferentes profissionais da saúde, no entendimento de que o processo saúde-doença é constituído pelos aspectos sociais, culturais, econômicos e biológicos que determinam a condição de vida da população.

Destaca-se que o formato pensado para os eventos mencionados pressupôs a participação da comunidade acadêmica e dos profissionais de campo para iniciar ou potencializar as práticas interdisciplinaridades. A diversidade dos temas estudados e das ações executadas considerou as demandas da UBS e os interesses do corpo discente, observando sempre as mudanças contemporâneas referentes tanto à Política de Saúde quanto às necessidades sociais. Isso propiciou enriquecimento teórico-metodológico mútuo na busca pela capacitação permanente e pela qualificação do serviço público de saúde, conforme os interesses dos usuários.

Considera-se que a interdisciplinaridade impõe, necessariamente, o estabelecimento de vínculos de integração no processo de trabalho, configurando-se mais do que a simples comunicação, podendo ser vislumbrada quando a comunicação ou diálogo sobre e entre saberes e práticas gerar uma integração mútua, constituindo novos saberes e novas práticas que busquem a resolução de um problema concreto (NOGUEIRA, 1998).

É reconhecível que houve esforços para a realização de iniciativas interdisciplinares, embora não tenha sido unânime entre os profissionais. No entanto, fora da vivência PET Saúde da Família, observou-se que na relação entre os profissionais da UBS, prevaleceram ações com base em equipe de cunho multidisciplinar. De acordo com Vasconcelos (1996 apud NOGUEIRA, 1998), significa que profissionais de diferentes áreas, mesmo compondo equipe, atuam isoladamente com grau mínimo de cooperação e troca de informações, coordenados administrativamente no plano institucional. Desse modo, a inter-relação ocorre mediante um sistema de referência e contra referência.

Inclusive, pode-se mencionar a fragilidade/insuficiência de reuniões de grupos Serv. Soc. \& Saúde, Campinas, SP v. 11, n. 1 (13), p. 113-132 jan./ jun. 2012 ISSN 1676-6806 
multidisciplinares para planejamento e monitoramento das ações entre os cursos de Medicina e de Serviço Social atuantes na UBS. Ao observar sob esse ângulo, pode-se constatar que as especialidades continuam mantendo seus limites e métodos cujo diálogo ocorre a partir das particularidades profissionais, ainda com poucos objetivos comuns.

Em algumas das ocasiões da implementação de atividades socioeducativas, reuniões de planejamento, dentre outras, supõe-se ter se estabelecido também uma relação pluridisciplinar à medida que, mesmo reconhecendo a importância e havendo a participação das diferentes categorias profissionais, as mesmas estabeleciam relações limitadas a conhecimentos de seu interesse (fragmentação dos saberes de caráter biológico, social, etc.), de modo a trocar pontos de vistas, cada um dentro de sua área de atuação e saber.

A partir da ótica dessas situações, observa-se a incoerência de objetivos comuns na condução do processo de trabalho, embora tenha ocorrido troca de informações entre os profissionais nos momentos de planejamento ou avaliação das ações e procedimentos. Essa atitude evidencia o prevalecimento, por parte de cada profissional, do desenvolvimento independente de suas ações.

Ao enfatizar a importância de um processo de trabalho interdisciplinar, destacase que as ações que o concretizam ocorrem quando, entre os integrantes da equipe, há reciprocidade, relações profissionais e de poder, tendentes à horizontalidade e com perspectivas de estratégias comuns para a ação (VASCONCELOS, 1996 apud NOGUEIRA, 1998). Convém resgatar Japiassu (1976) que destaca a interdisciplinaridade como trabalho coordenado e com objetivo comum, partilhado por vários ramos do saber, de forma integrada e convergente, cuja colaboração entre os diferentes profissionais não ocorre no multi e no pluri, pois é preciso o intercâmbio entre os saberes para além do monólogo e do diálogo paralelo. O resultado desse intercâmbio consiste em um processo interativo que reconfigura o conhecimento e propicia a cada profissional o enriquecimento teórico-prático adequado às reflexões produzidas a partir dos vários olhares disciplinares. Portanto, é preciso esclarecer que:

[...] nem todo trabalho em parceria é interdisciplinar, pois o desenvolvimento de trabalhos interdisciplinares não é algo que se faça em curto espaço de tempo e a contragosto de outros condicionantes. É normal que dois ou mais profissionais trabalhem juntos, através de diálogos e quando necessários, sobre o conteúdo do trabalho de ambos, sem que se faça disso uma ação interdisciplinar. Neste caso, 
estariam desenvolvendo uma parceria sobre um mesmo espaço profissional, onde diferentes formas de intervenção são produzidas, sem que haja uma proposta em comum sistematizada (SANTOS; MACHADO; SILVA, 2006, p. 52).

Apesar das restrições para a realização plena da interdisciplinaridade quanto ao envolvimento dos diferentes profissionais no desempenho (planejamento, ciclos de estudos, execução, etc.) dos eixos pactuados, pode-se observar que, nas ações desenvolvidas na UBS São José/Canaã, houve um empenho às iniciativas nessa direção. A participação dos usuários foi importante no estímulo ao trabalho da equipe multiprofissional que, no movimento para sanar suas dúvidas, articulou diversos conhecimentos disciplinares em prol de uma discussão mais ampla e enriquecedora sobre os assuntos e/ou necessidades em pauta.

O PET Saúde da Família - UFAL/Maceió tem demonstrado empenho à ação interdisciplinar, sendo este o ponto forte do grupo, evidenciado pelo pacto estabelecido que formou os grupos mistos de trabalho nas UBS. O processo de trabalho privilegiado no PET Saúde da Família (2010-2011) gerou vivências coletivas que garantiram conquistas de mobilizações, disciplinas e participações importantes, pois todas as áreas se mantiveram ativas na construção do projeto, planejamento, execução e avaliação. Sendo assim, diante da preocupação crescente de articulações diversas entre os cursos, pode-se dizer que, embora distante do desejado, o percurso sinalizou a interdisciplinaridade (BERNARDES et al., 2010).

Academicamente é necessário ampliar e consolidar esse processo iniciado pelo PET Saúde. O posicionamento das Unidades de Ensino e sua adesão à mudança deve oportunizar a formação generalista, crítica e interdisciplinar, ou seja, assumindo um novo compromisso político-pedagógico para a academia que transcenda as especialidades, sem anulá-las.

A partir da experiência acompanhada, adensaram-se expectativas em torno do exercício calcado na participação democrática, envolvendo diferentes sujeitos profissionais orientados para o atendimento centrado nas necessidades do usuário, considerando-os como sujeitos capazes de apresentar suas demandas e de decidir sobre as prioridades de ação para atendê-las.

Convém atentar que a resolutividade de demandas e a qualidade dos serviços prestados à população decorre também da organização destes, implicando em recursos 
financeiros, humanos, etc., o que requer a inter-relação e a corresponsabilidade sobre as quais a gestão política (nas três esferas de governo) deve tomar providências pertinentes, envolvendo profissionais cujo compromisso técnico constrói e escolhe medidas que potencializem suas ações, ouvindo os usuários e incluindo suas decisões no leque de ações da saúde, onde todos estimulam ativamente o controle social.

As ações profissionais interdisciplinares propiciam expor e analisar situações, reconhecendo as relações de interdependências e dialogando, de maneira a superar problemas comuns que dificultam a resolutividade das ações destinadas aos usuários. Portanto, é uma exigência à atitude profissional, principalmente porque não se pode perder o significado humano implícito nas ações profissionais, quase sempre fragmentado pela atitude intelectual e metodológica pautada nas especialidades do saber. Esse processo se realiza a longo prazo e requer novas habilidades para intervir sobre a dinâmica da realidade social, implicando no reconhecimento das limitações intelectuais presentes nas especialidades e incitando críticas construtivas.

Considera-se que, atuar em equipe é lidar com conflitos e tensões, sendo natural que existam momentos de divergências ideológicas (BORGES, 2006). Ainda que persistam dificuldades de haver diálogo entre o Serviço Social e a equipe de saúde para esclarecer suas atribuições e competências face à dinâmica de trabalho imposta nas UBS (RISO, 2010), o assistente social dispõe de capacidade para observar ângulos particulares na interpretação das condições de saúde do usuário, estimulando o exercício da interdisciplinaridade e executando encaminhamentos diferenciados em prol da intersetorialidade das ações em saúde.

Entende-se aqui que o profissional de Serviço Social tem uma formação específica que lhe confere capacidade técnica de apreender o social e o direito, buscando interdisciplinarmente a construção de práticas vinculadas ao social, presente no conceito ampliado de saúde (WIESE, 2003). Portanto, a possibilidade de o assistente social caminhar na direção dos interesses dos usuários, supõe contrapor-se ao trabalho espontâneo e/ou instintivo, superando o ecletismo e a fragmentação do saber e da ação.

Em sua intervenção profissional (específica ou interdisciplinar), é importante que assistente social atente para o funcionamento da instituição na qual atua, aos serviços que compõem o SUS e à dinâmica de outras instituições públicas e privadas, articulando ações que permitam o reconhecimento técnico de sua prática qualificada no processo de trabalho coletivo em saúde. Reconhece-se que sua prática não se Serv. Soc. \& Saúde, Campinas, SP v. 11, n. 1 (13), p. 113-132 jan./ jun. 2012 ISSN 1676-6806 
desenvolve independentemente das circunstâncias históricas e sociais que o determinam e sob as quais a saúde pública se desenvolve, bem como não se reduz ao atendimento individualizado das demandas e dos encaminhamentos, mas requer necessariamente o estímulo à participação na esfera pública em prol do controle social.

\section{CONCLUSÕES}

As ações profissionais sintetizam e expressam toda a formulação teórica, ética e técnica de uma profissão e não podem ser vistas de forma isolada porque articulam demandas e saberes diferentes. Na saúde, o cotidiano profissional é permeado por demandas singulares, coletivas e demandas de gestão e planejamento, a partir das quais o assistente social deve articular suas ações e a sua interação interdisciplinar.

O estudo possibilitou explorar a interdisciplinaridade como aspecto promotor da intersetorialidade entre políticas e serviços, na direção da efetivação do acesso integral ao direito à saúde. Essa relação implica no seguinte movimento: a busca pela satisfação das necessidades diretas postas às UBS e daquelas que extrapolam o âmbito da saúde, no entendimento de que se deve reconhecer e assimilar as interferências decorrentes das condições de vida da população. Portanto, mediante uma visão de totalidade, propiciada pela atitude interdisciplinar, é possível identificar os motivos pelos quais se deve articular as políticas públicas, considerando que a efetivação da integralidade depende da realização de interdisciplinaridade e intersetorialidade.

A categoria interdisciplinaridade considera a dinâmica da sociedade, exigindo novas atitudes diante de cada momento histórico e deve realizar inovações institucionais, profissionais e intelectuais na organização da atenção à saúde, considerando ainda os usuários como copartícipes desse processo, estabelecendo vínculos para potencializar a intervenção na comunidade.

A experiência acompanhada na UBS revelou que ainda predominam ações vinculadas ao modelo clínico-assistencial, sendo muitas as justificativas utilizadas pelos profissionais de saúde para manter o processo de trabalho fragmentado. Embora encontrem suporte nas legislações para defender e fundar uma prática diferenciada, contemplando o conceito ampliado de saúde, grande parte dos profissionais ignora e/ou não busca conhecer e criar condições objetivas para uma ação relacionada às necessidades cotidianas que modifiquem rotinas e práticas institucionais. 
Nesse contexto, evidencia-se a fragilidade das ações intersetoriais, principalmente pela ineficácia de um sistema e de protocolos de referência e contra referência no município, seja entre os níveis de Atenção Básica, Média e Alta Complexidade ou das demais políticas setoriais guiadas pelos determinantes sociais do processo saúde-doença. Aliado a isso, existem questões que perpassam o espaço institucional, como: inadequada infraestrutura, falta de insumos, insuficiente quantidade de recursos humanos, dentre outros aspectos que repercutem na qualidade dos serviços prestados aos usuários.

Vale destacar que a base da interação está na responsabilidade técnica assumida pelo profissional, no sentido de que todos participem do processo de atenção à saúde, envolvendo a experiência dos usuários como norteadora das ações, o exercício do controle social, dentre outros elementos que visam uma postura comprometida com a saúde pública como direito universal a ser realizado pelo Estado. Além do mais, deve-se compreender que a Atenção Básica, sendo um serviço local, possibilita aos profissionais estarem em contato direto com a realidade dos usuários e suas famílias, favorecendo o vínculo e ações centradas nas suas demandas concretas.

Portanto, mais do que refletir ou teorizar sobre a interdisciplinaridade, é preciso vivenciá-la. O momento de planejamento das ações é requisito básico aos profissionais, exigindo o conhecimento da realidade específica da população adstrita na abrangência da UBS para refletir sobre as ações de saúde prioritárias. Deve ser um movimento permanente, envolvendo monitoramento e avaliação para manter a vigilância e a reflexão crítica sobre o trabalho desenvolvido. Essa atitude também tem a intenção de desenvolver mecanismos mais participativos no âmbito das instituições de saúde. É fundamental que a equipe profissional supere o desafio de lidar com as diferenças, no sentido de não as considerar como entraves, mas como estímulo à mudança de práticas, com vistas a instituir ações eficazes.

O Serviço Social, ao inserir-se na equipe multiprofissional na Atenção Básica protagoniza a construção de ações coletivas que ultrapassam as práticas meramente curativas. Nessa direção, estimula a equipe no fortalecimento de ações que visam o alcance da saúde individual e coletiva e às suas determinações, as quais impelem o acesso aos bens e serviços indispensáveis à garantia dos direitos sociais, sobretudo em situações cujos determinantes advêm de condições precárias de vida. Envolve-se, portanto, interdisciplinarmente na resolução dos problemas de saúde através da sua Serv. Soc. \& Saúde, Campinas, SP v. 11, n. 1 (13), p. 113-132 jan./ jun. 2012 ISSN 1676-6806 
expertise em construir metodologias de ação direcionadas a indivíduos e famílias, articulando-as ao contexto social ao construir redes e ao estimular a inscrição, na esfera pública, das demandas que devem ser debatidas coletivamente em prol da garantia de direitos.

A pesquisa contribuiu para entender que o alcance da interdisciplinaridade somente acontecerá em processo, através de exercícios e pactuações cotidianas cujos obstáculos presentes na sua concretização são propensos a serem superados à medida que se enfrentam política e tecnicamente as fragilidades socioinstitucionais na viabilização de tais iniciativas e as resistências dos profissionais em aderir a essa prática. Portanto, fundar um processo de trabalho coletivo calcado na interdisciplinaridade, requer compromisso com o cuidado, a prevenção e a organização da prestação dos serviços, tendo em vista o cumprimento dos princípios e diretrizes do SUS, na efetivação do acesso ao direito à saúde.

Diante do estudo empreendido, espera-se adensar o debate no Serviço Social sobre o tema, contribuindo de forma geral para o processo incessante de construção do conhecimento e outras iniciativas na direção da interdisciplinaridade, tanto no âmbito de exercício profissional quanto na academia, contemplando o movimento crítico-reflexivo na relação entre teoria e prática ao desenvolver ações coletivas na saúde, sobretudo na construção de metodologias de ação consistentes e coerentes aos pressupostos aqui debatidos.

\section{REFERÊNCIAS}

ASSUMPÇÃO, I. Interdisciplinaridade: uma tentativa de compreensão do fenômeno. In: FAZENDA, I. C. A. (org.). Práticas interdisciplinares na escola. p. 23-35. São Paulo: Cortez, 1991.

BERNARDES, J. et al. A Construção do PET-Saúde da UFAL em Maceió: avanços e desafios para a formação em saúde. Relatório anual PET-Saúde da Família - campus Maceió: abril/2010-março/2011. UFAL, 2011.

BORGES, R; DOHN; O Trabalho de Equipe Interdisciplinar. In: CUTOLO, L. R. A. (org.). Manual Terapêutica Assistência à Família. Florianópolis: Associação Catarinense de Medicina, 2006. 
BRASIL. Constituição (1988). Constituição da República Federativa do Brasil: texto constitucional promulgado em 5 de outubro de 1988, com alterações adotadas pelas Emendas Constitucionais $n^{0}$ 1/92 a 56/2007 e pelas Emendas Constitucionais de Revisão nº 1 a 6/94. 464 p. Brasília: Senado Federal, Subsecretaria de Edições Técnicas, 2008.

BRASIL. Ministério da Saúde. Lei $\mathbf{n}^{\mathbf{0}}$ 8.080/90 e Lei complementar de $\mathbf{n}^{\mathbf{0}}$ 8142/90. 2. ed. MS - Assessoria de Comunicação Social. Brasília, 1991.

BRASIL. Ministério da Saúde. Política Nacional de Atenção Básica. Secretaria de Atenção à Saúde. Departamento de Atenção Básica, Secretaria de Atenção à Saúde. (Série Pactos pela Saúde 2006, v. 4). (Série A. Normas e Manuais Técnicos). 60 p. Brasília: Ministério da Saúde, 2006.

BRASIL. Ministério da Saúde. Programa Saúde da Família. Brasília 1998.

BRASIL. Conselho Nacional de Saúde. Resolução n. ${ }^{\circ}$ 218, de 06 de março de 1997.

BRAVO, M. I. de S. As Políticas Brasileiras de Seguridade Social: saúde, capacitação em Serviço Social e Política Social - Módulo 3. P. 3-116. Brasília, CEAD/UnB CFESS - ABEPSS, 2000.

CORBO, A. M. D.; MOROSINI, M. V. Saúde da família: história da recente organização da atenção à saúde. Escola Politécnica de Saúde Joaquim Venâncio (Org.). Textos de apoio em políticas de saúde. p. 60-84. Rio de Janeiro: Fiocruz, 2005.

COSTA, R. P. Interdisciplinaridade e equipes de saúde: concepções ano V - n. 8. p. 107-124. Barbacena: Mental (Periódicos Eletrônicos em Psicologia), 2007. Disponível em: <http://pepsic.bvsalud.org/pdf/mental/v5n8/v5n8a08.pdf> . Acesso em: 20/03/2011. FLICK, U. Uma introdução à pesquisa qualitativa. 2.ed. Porto Alegre: Bookman, 2004.

JAPIASSU, H. Interdisciplinaridade e patologia do saber. Rio de Janeiro: Imago, 1976.

KOLLER, S. L., organizadora. Adolescência e psicologia: concepções, práticas e reflexões críticas. 144, p. Rio de Janeiro (RJ): Conselho Federal de Psicologia, 2002.

NOGUEIRA, V. M. R. A Importância da Equipe Interdisciplinar no Tratamento de Qualidade na Área da Saúde. Katálysis. v. 8, nº 2 j/dez. Florianópolis, SC, 1998.

NORA, C. R. D. et al. Sala de espera uma ferramenta para efetivar a Educação em saúde. Revista Saúde e Pesquisa, v. 2, n. 3, p. 397-402, set./dez. 2009 - ISSN 19831870. 
OLIVEIRA, I. de et al. 2010. Projeto de Intervenção na Unidade de Saúde da Família São José: Incentivo ao Aleitamento Materno no Combate à Mortalidade Infantil.

RIBEIRO. S. P. et al. O Cotidiano Profissional do Assistente Social no Programa Saúde da Família em Campina Grande. Katálysis v. 8, n 2 j/dez. Florianópolis - SC, 2005.

RISO, S. Atuação do Assistente Social na Saúde. Disponível em: http://wwwsandrarizo.blogspot.com/2010/04/atuacao-do-assistente-social-nasaude.html. Acesso em: 17/3/2011.

SANTOS, A. B. V.; MACHADO, F. M. T. d e L.; SILVA, M. C. A Interdisciplinaridade no Juizado da Infância e da Juventude de Maceió: uma prática em discussão. Trabalho de Conclusão de Curso, Maceió - FSSO/UFAL. 2006. SANTOS, B. R. L. dos; THIESEN, F. V. O Programa de Educação pelo Trabalho para a Saúde fortalecendo a interdisciplinaridade na formação dos profissionais da área da saúde. Revista Ciência \& Saúde, Porto Alegre, v. 3, n. 1, p. 1, jan./jun. PUCRS, 2010. SANTOS, J. dos; SANTOS, M. B. A Política de Atenção Básica: Aproximação com o debate sobre a efetivação do SUS e a Participação do Assistente Social na ESF. Trabalho de Conclusão de Curso. Maceió - UFAL, 2010.

SANTOS, K. J. N. dos et al. O Serviço Social na Unidade de Saúde São José/Canaã: relato da experiência no pet saúde da família. (2010-2011). UFAL, 2011.

SILVA, M. M. da. O Serviço Social e a Interdisciplinaridade na Atenção Básica à Saúde. Monografia (Trabalho de Conclusão de Curso). Maceió - FSSO/UFAL, 2011.

WIESE, M. L. A categoria social no âmbito das práticas profissionais no Programa Saúde da Família do município de Blumenau. Dissertação (Mestrado em Serviço Social) - Faculdade de Serviço Social, Universidade Federal de Santa Catarina, Florianópolis, 2003. 
